\title{
Descriptive Epidemiology and Survival Analysis of Prolactinomas and Cushing's Disease in Korea
}

\author{
Jin Sun Park ${ }^{1,2, *}$, Soo Jin Yun ${ }^{1,2}$, Jung Kuk Lee ${ }^{3}$, So Young Park ${ }^{1}$, Sang Ouk Chin ${ }^{1}$ \\ ${ }^{1}$ Department of Endocrinology and Metabolism, Kyung Hee University School of Medicine; ${ }^{2}$ Department of Medicine, \\ Graduate School of Medicine, Kyung Hee University, Seoul; ${ }^{3}$ Department of Biostatistics, Yonsei University Wonju College of \\ Medicine, Wonju, Korea
}

Background: Only a few studies have established the epidemiology of prolactinoma and Cushing's disease in Korea. Furthermore, the incidence of these disease are increasing than before associated with the development of technologies. This study was designed to evaluate the epidemiology of prolactinoma and Cushing's disease and their survival analysis according to treatment.

Methods: The nationwide, population-based study evaluated incidence and prevalence of prolactinoma and Cushing's disease using de-identified claims data in The Korean Health Insurance Review and Assessment Service database between 2013 and 2017. The survival analysis investigated regarding treatment over a period of 6 years. A log-rank test and Cox proportional hazard regression analysis were used.

Results: The 6,056 patients with newly diagnosed prolactinoma and 584 patients with Cushing's disease were recorded between 2013 and 2017. The annual incidence of prolactinoma was 23.5 cases per million, and its prevalence was 82.5 cases per million, and 2.3 cases per million/year and 9.8 cases per million for Cushing's disease. The survival benefit was insignificant in prolactinoma according to treatment, but treatment of Cushing's disease ameliorated the survival rate significantly.

Conclusion: Overall, the incidence of prolactinoma and Cushing's disease was similar with those found previously, but the prevalence of two diseases were inconsistent when compared with the early studies. The present study also proposed necessity of treatment in Cushing's disease for improving the survival rate.

Keywords: Prolactinoma; Pituitary ACTH hypersecretion; Incidence; Prevalence; Survival analysis; Epidemiology

\section{INTRODUCTION}

A pituitary adenoma (PA) has been considered to be a rare disease in the past; however, it is now reported more frequently than before owing to the development of technologies associated with radiological and hormonal diagnostic techniques [1-3].

Received: 16 February 2021, Revised: 8 April 2021, Accepted: 28 April 2021

Corresponding author: Sang Ouk Chin

Department of Endocrinology and Metabolism, Kyung Hee University School of Medicine, 26 Kyungheedae-ro, Dongdaemun-gu, Seoul 02447, Korea Tel: +82-2-958-8200, Fax: +82-2-968-1848, E-mail: jan27th@khu.ac.kr

*Current affiliation: Department of Cardiology, Asan Medical Center, University of Ulsan College of Medicine, Seoul, Korea
The socioeconomic burden of these diseases is also increasing with the high morbidity and mortality rates [3]. In Korea, previously reported data have revealed a deterioration of the burden of these diseases on health care [4]. Although the epidemiologic study is one of the first tasks for understanding a disease, the studies on PAs in Korea were insufficient, and most of the pre-

\section{Copyright $(\odot) 2021$ Korean Endocrine Society}

This is an Open Access article distributed under the terms of the Creative Commons Attribution Non-Commercial License (https://creativecommons.org/ licenses/by-nc/4.0/) which permits unrestricted non-commercial use, distribution, and reproduction in any medium, provided the original work is properly cited. 
vious studies analyzed Western populations. In addition, the earlier studies have shown inconsistent results because most of these were based on small-population, cross-sectional design studies, and their data sources were a single surgical center or cancer registry [1-3,5-9].

PAs are classified as macroadenomas ( $>10 \mathrm{~mm}$ in diameter) or microadenomas ( $\leq 10 \mathrm{~mm}$ in diameter) depending on their diameter [10,11]. PAs are also divided into functional or nonfunctional adenomas depending on their hormonal hyper-secretory capacity [12]. Functional PAs are categorized into several subtypes according to the hormone secreted by each tumor. Each subtype has different morbidity and mortality rates. Unlike a number of epidemiological studies regarding acromegaly [1,69,13-22], there were few studies about morbidity and mortality associated with prolactinomas and Cushing's disease (CD). A prolactinoma is known to be one of the most frequent subtypes of PA, which accounts for $40 \%$ to $50 \%$ of PAs. CD is rare, accounting for $4 \%$ to $6 \%$ of PAs and has a high cardiovascular mortality rate [2,23-26]. Despite their importance in public health care, epidemiologic data on morbidity and mortality of these two diseases is not enough, even with incoherent results. Furthermore, some of non-functional PAs, especially macroadenomas, may be capable of secreting prolactin [27-29]; which makes it difficult to determine the accurate epidemiology of pure prolactinomas. Likewise, a low incidence of CD challenges investigators to differentiate from non-pituitary Cushing's syndrome (CS); therefore, a well-equipped diagnostic laboratory system and protocol with experienced endocrinologist are mandatory to guarantee diagnostic accuracy leading to the proper analysis of epidemiologic data for CD.

Furthermore, since epidemiologic studies depend on population-specific registries with regional differences in practices, such as diagnostic practices, reporting patterns, and case definitions [30], there are limitations to accepting the results of previous studies based on different populations. Therefore, it was necessary to conduct an analysis using Korean population-based data. The Korean Health Insurance Review and Assessment Service (HIRA), which was introduced in 1989, collects claims data for the purpose of national insurance coverage in Korea. This data includes health care utilization, health screening, and mortality for the entire population of Korea that includes over 50 million people based on the HIRA database, we conducted a nationwide, population-based study evaluated the epidemiology of prolactinoma and CD, along with their recent trends, in Korea,

\section{METHODS}

\section{Data collection}

The HIRA database includes insurance claims data of the entire Korean population that is covered by the national healthcare insurance system and is open to the public, with the aim of contributing towards establishing knowledge related to health care. As the database is primarily for insurance claims, the establishment of appropriate operational definitions using assessment codes such as laboratory test, procedure, and drug prescription, in addition to the diagnostic code is inevitable for the reliability of our analysis. Therefore, in the present study, we extracted deidentified claims data containing the treatment history of all patients with prolactinomas or CD who visited a healthcare facility. To identify suitable subjects for analysis, we established an operational definition using the International Classification of Disease 10th revision (ICD-10) codes. In order to assure more accurate operational definitions in our study, we cross matched the benefit extension policy (BEP) codes with the HIRA codes. The BEP was established to support medical expenses for patients with rare and incurable diseases such as cancers, rare genetic disorders, and so on [31]. The BEP code is mandatory to exempt certain amount of medical expenses for managing registered diseases. Double comparison with the HIRA dataset and the BEP codes is believed to improve the reliability of data extracted in our study population.

In this study, patients having diagnostic codes (ICD-10) of hyperprolactinemia (E22.1) and benign neoplasm of the pituitary gland (D35.2) with the corresponding BEP codes (V162 for PAs and V112 for hyperprolactinemia) for prolactinomas were identified as patients with prolactinoma. Patients with CD were defined as those who were registered with the diagnostic codes of pituitary-dependent CD (E24.0) and benign neoplasm of the pituitary gland (D35.2) along with the corresponding BEP code for PAs (V162) and CD (V114). In addition, patients registered with the code of other CS or CS unspecified (E24.8) were also included in the study only if they had a code for both CD (E24.0) and benign neoplasm of the pituitary gland (D35.2) at the same time.

The present study included all patients with prolactinoma and CD who were registered in the HIRA database and had a history of receiving outpatient care or hospitalization between January 2009 and December 2017. The annual incidence and prevalence rates were analyzed between January 2013 and December 2017. For the annual incidence rate, the period from 2009 to 2012 was set as the washout period. We used the resident registration de- 
mographics established by Statistics Korea as the denominator.

Patients with newly diagnosed prolactinoma or CD between January 2011 and December 2012 were extracted, and the survival rates of these patients were estimated for the period from January 2013 to December 2017. Since one of the previous studies which investigated the epidemiology of PAs in Korea employed the analysis period between 2009 and 2013 [4], the longest period we can manage was 5 years to avoid overlapping the study period. In addition, in order to establish the secure time period for the adequate survival analysis, we were obliged to investigate the group of patients newly diagnosed between 2011 and 2012 with wash out period between 2009 and 2010, different from those used for the analysis of the aforementioned epidemiology. The differences in survival probability according to treatment were compared. The treated group was defined as patients with any record of treatment including the first-generation somatostatin analogues such as octreotide or lanreotide, surgery such as trans-sphenoidal approaches, and radiation therapy including gamma knife surgery after their diagnostic codes were entered, while the untreated group included those without any corresponding treatment record but only with diagnostic codes.

The present study was established in accordance with the guidelines of the Declaration of Helsinki and approved by the Kyung Hee University Hospital Institutional Review Board
(KHUH 2018-11-001). Informed consent from the subjects was waived due to the retrospective design of this study.

\section{Statistical analysis}

Hazard ratios (HRs) and 95\% confidence intervals (CIs) for mortality were evaluated using a log-rank test and Cox proportional hazard regression analysis. Multivariate model analysis was performed after adjusting for age, sex, and income level. The survival period was defined as the time between the first or initial day of observation and the day when a new clinical event occurred or the end of the observation period on December 31, 2017. Patients treated before the initial diagnosis of prolactinomas or CD were excluded from the analysis. The results were considered statistically significant if the $P$ value was $<0.05$. Statistical analyses were performed using SAS software version 9.4 (SAS Institute, Cary, NC, USA).

\section{RESULTS}

\section{Epidemiologic data \\ Prolactinoma}

Between January 2013 and December 2017, 6,056 patients were newly diagnosed with prolactinoma, with approximately 1,000 patients diagnosed annually (Table 1, Fig. 1A). The annual incidence was 23.5 cases per million, and the prevalence was 82.5

\begin{tabular}{|c|c|c|c|c|c|}
\hline & 2013 & 2014 & 2015 & 2016 & 2017 \\
\hline \multicolumn{6}{|l|}{ Sex } \\
\hline Male & $86(8)$ & $101(9.1)$ & $105(8.8)$ & $89(6.6)$ & $98(7.4)$ \\
\hline Female & $990(91.9)$ & $1,005(90.8)$ & $1,092(91.1)$ & $1,255(93.1)$ & $1,227(92.6)$ \\
\hline Unknown & 1 & 1 & 2 & 4 & \\
\hline \multicolumn{6}{|l|}{ Age } \\
\hline 0-19 & $44(4.1)$ & $41(3.7)$ & $48(4)$ & $72(5.3)$ & $64(4.8)$ \\
\hline $20-29$ & $213(19.8)$ & $247(22.3)$ & $239(19.9)$ & $276(20.5)$ & $307(23.2)$ \\
\hline $30-39$ & $409(38)$ & $403(36.4)$ & $428(35.7)$ & $492(36.5)$ & $464(35)$ \\
\hline $40-49$ & $277(25.7)$ & $263(23.8)$ & $335(27.9)$ & $335(24.9)$ & $345(26)$ \\
\hline $50-59$ & $89(8.3)$ & $107(9.7)$ & $101(8.4)$ & $115(8.5)$ & $99(7.5)$ \\
\hline $60-69$ & $27(2.5)$ & $24(2.2)$ & $30(2.5)$ & $34(2.5)$ & $30(2.3)$ \\
\hline $70-79$ & $15(1.4)$ & $18(1.6)$ & $15(1.3)$ & $16(1.2)$ & $12(0.9)$ \\
\hline$>79$ & 2 & $3(0.3)$ & $1(0.1)$ & $4(0.3)$ & $4(0.3)$ \\
\hline Unknown & 1 & 1 & 2 & 4 & \\
\hline Total & 1,077 & 1,107 & 1,199 & 1,348 & 1,325 \\
\hline
\end{tabular}



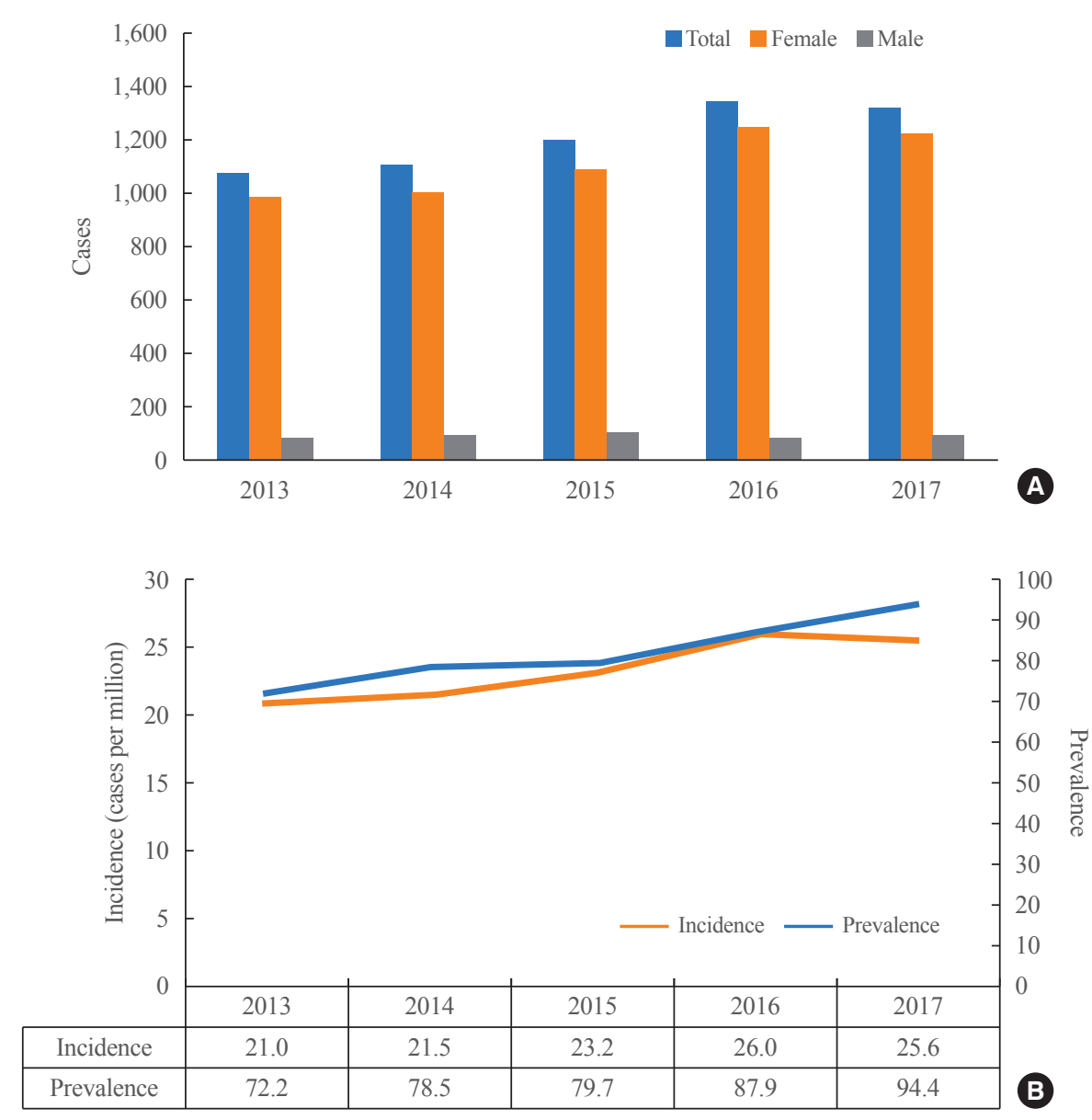

Fig. 1. Incidence rate of prolactinoma in Korea during 2013 to 2017: (A) number of newly diagnosed patients with prolactinoma (B) incidence and prevalence rates of prolactinoma per million.

cases per million. In 2016, the incidence was 26.0 cases per million, and the prevalence tended to increase during this period; in 2017, 94.4 cases per million were observed (Fig. 1B). Of the newly diagnosed patients, $91.9 \%$ were women. The highest incidence was observed in individuals in their 40s, accounting for $36.3 \%$ of the total patients, while elderly patients aged 80 years or more demonstrated an incidence rate of $<1 \%$, and adolescents accounted for approximately $4.3 \%$ of total cases (Table 1).

\section{Cushing's disease}

Between January 2013 and December 2017, a total of 584 newly diagnosed CD patients were recorded, with more than 100 cases each year (Table 2, Fig. 2A). Majority of patients were females, accounting for $88.0 \%$ of all cases. The number of patients in each age group were evenly distributed between 20 and 70 years, accounting for approximately $10 \%$ to $20 \%$ of the total cases (Table 2). The annual incidence of $\mathrm{CD}$ was 2.3 cases per million, and its prevalence was 9.3 cases per million (Fig. 2B).

\section{Survival analysis}

From January 2013 to December 2017, there were a total of $35 / 1,685$ cases with death were noted in patients with prolactinoma, and 20/1,172 cases were shown to undergo either medical or surgical treatment, and 15/511 cases appeared to be untreated. This led to a slightly lower mortality rate in the treated group than those in the untreated group, but this difference was not statistically significant (HR, 1.471; 95\% CI, 0.745 to 2.902; $P=0.1066$ ) (Fig. 3A). On the other hands, there were a total of $14 / 117$ cases with death were noted in patients with $\mathrm{CD}$, and 9/102 cases were shown to undergo either medical or surgical treatment, and 5/15 cases were found to be untreated. This resulted in a significantly lower mortality rate in the treated group than those in the untreated group (HR, 4.648; 95\% CI, 1.391 to 8.183; $P=0.0029$ ) (Fig. 3B). 
Table 2. The Number of Cases with Cushing's Disease in Korea According to Sex and Year

2013

2014

2015

19 (12.9)

14 (12.5)

98 (87.5)

128 (87.1)

Female

Unknown

Age

0-19

20-29

30-39

$40-49$

$50-59$

60-69

70-79

$>79$

Unknown

Total

Values are expressed as number (\%).

$\begin{array}{ccccc}4(3.6) & 8(5.4) & 5(5) & 5(4.5) & 2(1.8) \\ 17(15.2) & 14(9.5) & 10(9.9) & 14(12.7) & 14(12.3) \\ 30(26.8) & 26(17.7) & 18(17.8) & 21(19.1) & 24(21.1) \\ 18(16.1) & 34(23.1) & 23(22.8) & 20(18.2) & 19(16.7) \\ 19(17) & 26(17.7) & 23(22.8) & 23(20.9) & 30(26.3) \\ 13(11.6) & 24(16.3) & 15(14.9) & 11(10) & 15(13.2) \\ 8(7.1) & 13(8.8) & 7(6.9) & 13(11.8) & 9(7.9) \\ 3(2.7) & 2(1.4) & & 3(2.7) & 1(0.9) \\ 112 & & & & 114\end{array}$

$\begin{array}{lll}23(22.8) & 22(20) & 25(21.9) \\ 78(77.2) & 88(80) & 89(78.1)\end{array}$

$89(78.1)$

2017
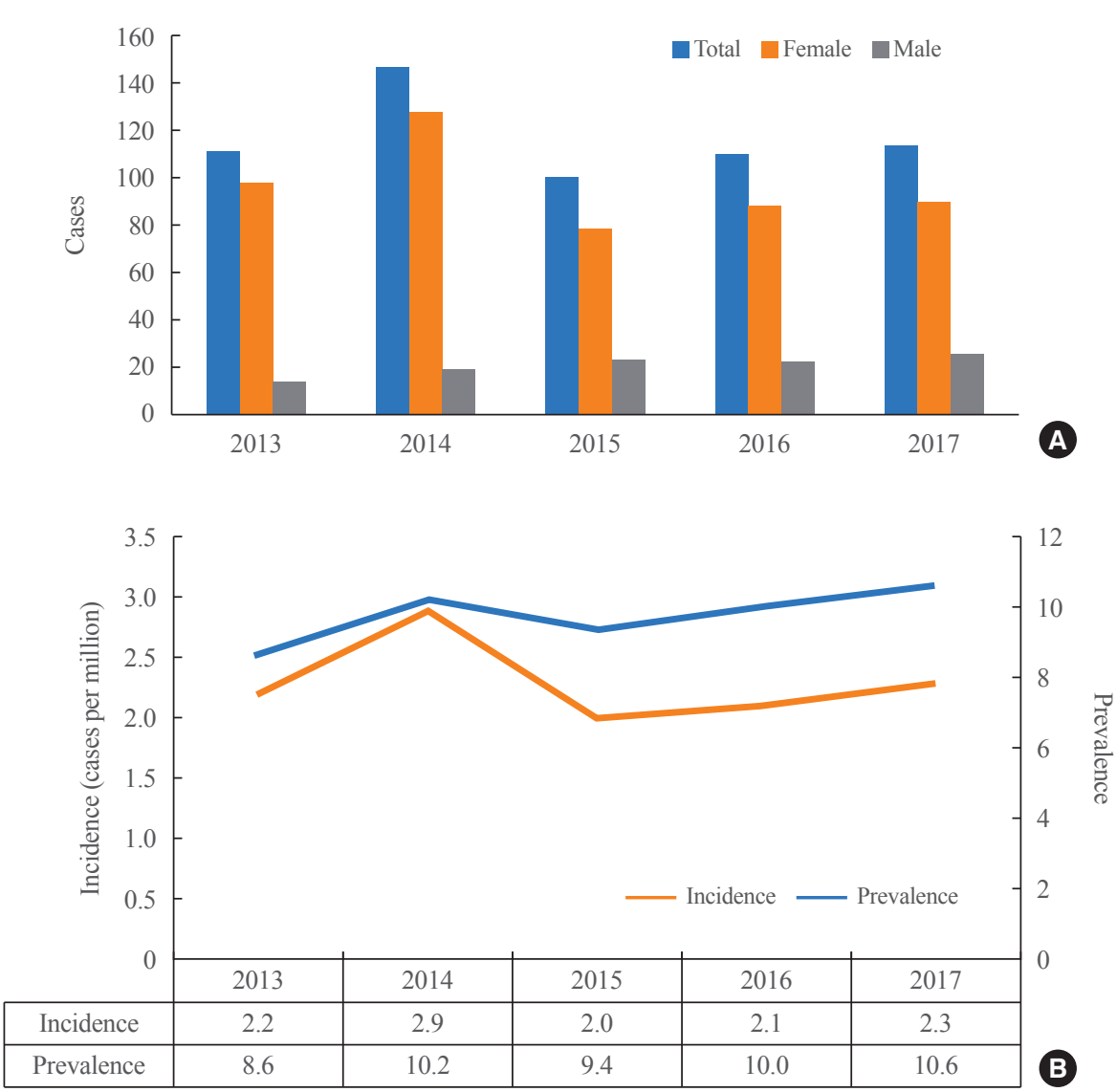

Fig. 2. Incidence rate of Cushing's disease in Korea during 2013 to 2017: (A) number of newly diagnosed patients with Cushing's disease (B) incidence and prevalence rates of Cushing's disease per million. 

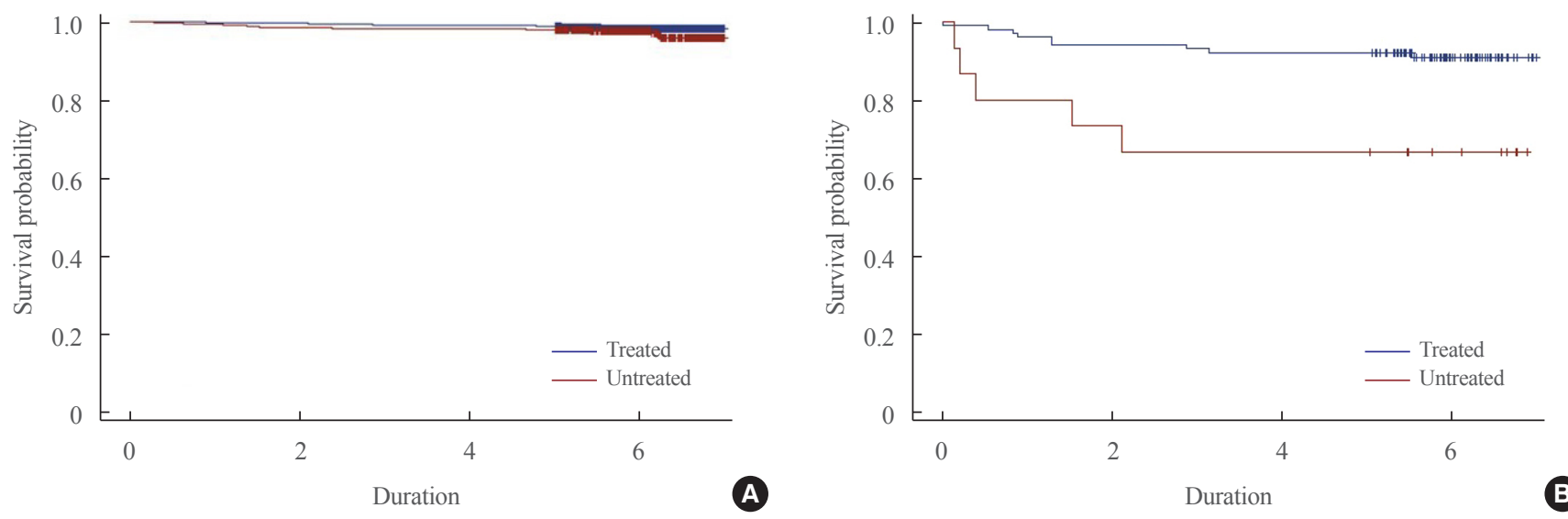

Fig. 3. Probability of survival in (A) prolactinoma (B) Cushing's disease between treated and untreated patients (curve difference, $P=0.1066$ for prolactinoma; $P=0.0029$ for Cushing's disease).

\section{DISCUSSION}

This study was designed to investigate the epidemiology of prolactinomas and $\mathrm{CD}$ in Korea using a nationwide, populationbased study based on the HIRA database, which identified 6,056 cases of prolactinomas and 584 cases of CD between 2013 and 2017. The incidence of prolactinomas was 23.5 cases per million, and its prevalence was 82.5 cases per million. The incidence of $\mathrm{CD}$ was 2.3 cases per million, and its prevalence was 9.8 cases per million. The survival rate of patients with prolactinoma who were treated was slightly higher than that of untreated patients, but the difference was insignificant. However, the survival rate of treated patients with CD was significantly higher than that of untreated patients.

There are a few population-based studies related to the epidemiology of prolactinomas. Gruppetta et al. [7] and Agustsson et al. [13], reported that the incidence of prolactinoma was 20 cases per million in the population of Malta and Iceland, respectively, which is similar to that in the present study. However, the prevalence in these studies were considerably different from each other, with Gruppetta et al. [7] reporting 350 cases per million and Agustsson et al. [13] reporting 543.7 cases per million. Moreover, a community-based study in Banbury in the UK reported a prevalence of 444 cases per million for prolactinoma [6]. The reason for this inconsistency was possibly because there were differences in the population size targeted by each study, data source, and methods of analysis. In Korea, two studies have been reported which investigated the epidemiology of PAs using the HIRA database. Park et al. [4] reported that the incidence of hyperprolactinemia was 15 cases per million, with the prevalence increasing from 38.5 to 68.6 cases per million between
2009 and 2013, while Oh et al. [25] reported only the incidence, which was 16 cases per million. The disagreement between studies using the same database with respect to the incidence is possibly due to differences in the operational definition of the disease in terms of different combination of diagnostic and BEP codes in each study [4,25]. In addition, previous results in Korea demonstrated that the highest incidence rate was observed in patients in their 30s, and a sharp decline of the incidence rate was observed among older individuals [4]. Similarly, in our study, the patients in their 30s accounted for the largest proportion among the entire patients (36.3\%); the high proportion was maintained until the $40 \mathrm{~s}$ but decreased thereafter. The incidence of females were a 10-fold higher than that of males, but this sex disparity tended to become equalized in patients aged $>50$ years $[1,4,6]$. One hypothesis for this phenomenon is that the clinical symptoms and signs related to amenorrhea-galactorrhea syndrome are more definite in women than in men [25].

Since CD is rare and difficult to diagnose, most epidemiologic studies have focused on the entire spectrum of endogenous CS. Gruppetta et al. [7] reported that in Malta the incidence of $\mathrm{CD}$ was 0.7 cases per million, and the prevalence was 16.8 cases per million. Agustsson et al. [13] reported that the incidence and prevalence in Iceland were five cases per million for women and 62 cases per million, respectively. The community-based study at Banbury in the UK reported only a prevalence of 12 cases per million [6]. Another community-based study in the residents of Vizcaya in Spain reported that the incidence of CD was 2.4 cases per million, but the prevalence was significantly different at 39.1 cases per million [2]. The incidence and prevalence of CD have been mostly inconsistent according to the studies varied between the studies, possibly due to the charac- 
teristically low incidence of CD with different study designs and small size of populations in previous studies. In addition, it should be emphasized for the difficulty in differentiating between CD and CS. In the case of some studies conducted before the 90 s or the early 2000s, magnetic resonance imaging was not used to diagnose PAs, and laboratory techniques may not have been sufficiently accurate. Therefore, there are many limitations to the comparison between the results from these studies and the results of our study based on recent data. Female predominance in patients with $\mathrm{CD}$ was observed as seen in previous studies $[2,9,13,24]$. In addition, newly diagnosed patients were evenly distributed between 20 and 60 years of age, indicating the same trend as in previous studies [2].

Despite the low mortality rates observed among patients with prolactinoma who were treated, there was no significant difference in mortality rates when compared with that of untreated patients. Although the most common cause of death in patients with PA is cardiovascular disease (CVD) and its associated conditions [3], the incidence of CVD in patients with prolactinoma has been reported to be lower than those with adrenocorticotropic hormone-, thyroid stimulation hormone-secreting adenomas, or non-functional adenomas [25]. In addition, the mortality rate of patients with prolactinoma was similar to that of the general population [25], which may lead to insignificant difference in mortality regardless of treatment. On the other hand, in patients with $\mathrm{CD}$, significant improvement was observed in the mortality rate of patients in the treated group. $\mathrm{CD}$ is known to have a high CVD-associated mortality rate because of impaired glucose metabolism and persistent hypertension caused by neurohormonal effects [2,23-26]. Few studies have demonstrated the long-term mortality in $\mathrm{CD}$, with conflicting results. Colao et al. [23] documented that CVD risk factors such as body mass index, blood pressure, and fasting blood glucose level were increased in patients with $\mathrm{CD}$ even after 5 years of successful treatment when compared with that age- and sex-matched controls, which presumably played a role to rather aggravate the CVD risks. However, this was a small-scale study of 15 patients with $\mathrm{CD}$ who were cured. A previous population-based study was consistent with the results of our study, which suggested long-term survival after successful transsphenoidal surgery for CD was not markedly different compared to the background population [24], and another case series study was also in close agreement with ours [26].

Our study has certain limitations. First, the HIRA database may not be optimal for estimating the incidence and prevalence of diseases, since the data have been collected for tracking med- ical service claims and reimbursement [32]. Moreover, the accuracy of the diagnostic code entered by each physician cannot be guaranteed, possibly leading to over- or under-estimation. To improve the reliability and accuracy of the extracted data, an operational definition was established using the simultaneous application of BEP and ICD-10 codes. It has been previously reported that the diagnostic accuracy of operational definitions was improved by combining the HIRA database and BEP codes [25], which showed that re-evaluation of medical records of patients who were extracted by operational definition resulted in the accuracy of diagnostic codes had 93\% sensitivity and 94\% specificity [25]. Unfortunately, we were not able to apply the same method to evaluate the accuracy of our operational definition as done in the previous study [25], because the raw dataset initially provided by the HIRA was anonymous after de-identification and was allowed to access in the strictly authorized area only, not eligible for comparing with data in our hospital or finding out the detailed individual information of each subjects. Second, our survival analysis was performed after adjusting for age, sex and income levels, but for more accurate analysis it was necessary to perform the survival analysis after adjustment with additional covariates and cause of death, which may possibly undermine the representativeness of the actual clinical course between treated and untreated group. Finally, in patients with $\mathrm{CD}$, a significant improvement in survival was observed in the treated group compared to that in the untreated group; however, a comparative analysis with the general population was not performed. Despite using the study design similar with previous two studies in Korea based on same database, however, it should be of note that our study attempted to investigate the most recent trend of the epidemiology of prolactinoma and CD. In addition, it is meaningful to mention that our study compared the mortality between the treated and untreated group, but not general population to observe the effect of treatment more directly.

In conclusion, the annual incidence of prolactinoma was similar to that reported in previous studies; however, its prevalence was considerably different. In patients with $\mathrm{CD}$, the annual incidence was also similar to that in previous studies although its prevalence was lower than that in other countries. In addition, a significant difference in survival rates was observed between treated and untreated patients with $\mathrm{CD}$, which sheds light on the role of the treatment in improving 281 the survival rate in CD. We are currently planning to conduct a comparative analysis of the mortality rate with the general population with long term follow-up. The epidemiology of other types of PA, including acromegaly, thyrotropin-producing PA, is also being evaluated. 


\section{CONFLICTS OF INTEREST}

No potential conflict of interest relevant to this article was reported.

\section{ACKNOWLEDGMENTS}

All authors would like to thank the Committee of Research of the Korean Endocrine Society for providing support for this study. The analysis was performed with the permission for data utilization from the National Health Insurance Service in Korea (permission No.: NHIS-2019-1-137).

\section{AUTHOR CONTRIBUTIONS}

Conception or design: S.Y.P., S.O.C. Acquisition, analysis, or interpretation of data: J.S.P., J.K.L., S.O.C. Drafting the work or revising: J.S.P., S.J.Y., S.O.C. Final approval of the manuscript: S.O.C.

\section{ORCID}

Jin Sun Park https://orcid.org/0000-0001-8831-8344

Sang Ouk Chin https://orcid.org/0000-0001-5914-3653

\section{REFERENCES}

1. Daly AF, Rixhon M, Adam C, Dempegioti A, Tichomirowa MA, Beckers A. High prevalence of pituitary adenomas: a cross-sectional study in the province of Liege, Belgium. J Clin Endocrinol Metab 2006;91:4769-75.

2. Etxabe J, Vazquez JA. Morbidity and mortality in Cushing's disease: an epidemiological approach. Clin Endocrinol (Oxf) 1994;40:479-84.

3. Nilsson B, Gustavasson-Kadaka E, Bengtsson BA, Jonsson B. Pituitary adenomas in Sweden between 1958 and 1991: incidence, survival, and mortality. J Clin Endocrinol Metab 2000;85:1420-5.

4. Park KH, Choi JG, Tae ES, Song SO, Nam JY, Song YD. Rare intractable pituitary diseases: analysis on their epidemiology and use of benefit extension policy (No. 2015-20025). Goyang: National Health Insurance Service Ilsan Hospital; 2015.

5. Day PF, Loto MG, Glerean M, Picasso MF, Lovazzano S, Giunta DH. Incidence and prevalence of clinically relevant pituitary adenomas: retrospective cohort study in a Health
Management Organization in Buenos Aires, Argentina. Arch Endocrinol Metab 2016;60:554-61.

6. Fernandez A, Karavitaki N, Wass JA. Prevalence of pituitary adenomas: a community-based, cross-sectional study in Banbury (Oxfordshire, UK). Clin Endocrinol (Oxf) 2010; 72:377-82.

7. Gruppetta M, Mercieca C, Vassallo J. Prevalence and incidence of pituitary adenomas: a population based study in Malta. Pituitary 2013;16:545-53.

8. Raappana A, Koivukangas J, Ebeling T, Pirila T. Incidence of pituitary adenomas in Northern Finland in 1992-2007. J Clin Endocrinol Metab 2010;95:4268-75.

9. Tjornstrand A, Gunnarsson K, Evert M, Holmberg E, Ragnarsson $\mathrm{O}$, Rosen $\mathrm{T}$, et al. The incidence rate of pituitary adenomas in western Sweden for the period 2001-2011. Eur J Endocrinol 2014;171:519-26.

10. Buchfelder M, Schlaffer S. Imaging of pituitary pathology. Handb Clin Neurol 2014;124:151-66.

11. Raverot G, Jouanneau E, Trouillas J. Management of endocrine disease: clinicopathological classification and molecular markers of pituitary tumours for personalized therapeutic strategies. Eur J Endocrinol 2014;170:R121-32.

12. Arafah BM, Nasrallah MP. Pituitary tumors: pathophysiology, clinical manifestations and management. Endocr Relat Cancer 2001;8:287-305.

13. Agustsson TT, Baldvinsdottir T, Jonasson JG, Olafsdottir E, Steinthorsdottir V, Sigurdsson G, et al. The epidemiology of pituitary adenomas in Iceland, 1955-2012: a nationwide population-based study. Eur J Endocrinol 2015;173:655-64.

14. Dal J, Feldt-Rasmussen U, Andersen M, Kristensen LO, Laurberg P, Pedersen L, et al. Acromegaly incidence, prevalence, complications and long-term prognosis: a nationwide cohort study. Eur J Endocrinol 2016;175:181-90.

15. Bengtsson BA, Eden S, Ernest I, Oden A, Sjogren B. Epidemiology and long-term survival in acromegaly. A study of 166 cases diagnosed between 1955 and 1984. Acta Med Scand 1988;223:327-35.

16. Bex M, Abs R, T'Sjoen G, Mockel J, Velkeniers B, Muermans $\mathrm{K}$, et al. AcroBel-the Belgian registry on acromegaly: a survey of the 'real-life' outcome in 418 acromegalic subjects. Eur J Endocrinol 2007;157:399-409.

17. Burton T, Le Nestour E, Neary M, Ludlam WH. Incidence and prevalence of acromegaly in a large US health plan database. Pituitary 2016;19:262-7.

18. Etxabe J, Gaztambide S, Latorre P, Vazquez JA. Acromegaly: an epidemiological study. J Endocrinol Invest 1993;16: 
181-7.

19. Hoskuldsdottir GT, Fjalldal SB, Sigurjonsdottir HA. The incidence and prevalence of acromegaly, a nationwide study from 1955 through 2013. Pituitary 2015;18:803-7.

20. Kwon O, Song YD, Kim SY, Lee EJ; Rare Disease Study Group, Science and Research Committee, Korean Endocrine Society. Nationwide survey of acromegaly in South Korea. Clin Endocrinol (Oxf) 2013;78:577-85.

21. Mestron A, Webb SM, Astorga R, Benito P, Catala M, Gaztambide $\mathrm{S}$, et al. Epidemiology, clinical characteristics, outcome, morbidity and mortality in acromegaly based on the Spanish Acromegaly Registry (Registro Espanol de Acromegalia, REA). Eur J Endocrinol 2004;151:439-46.

22. Ritchie CM, Atkinson AB, Kennedy AL, Lyons AR, Gordon DS, Fannin T, et al. Ascertainment and natural history of treated acromegaly in Northern Ireland. Ulster Med J 1990; 59:55-62.

23. Colao A, Pivonello R, Spiezia S, Faggiano A, Ferone D, Filippella M, et al. Persistence of increased cardiovascular risk in patients with Cushing's disease after five years of successful cure. J Clin Endocrinol Metab 1999;84:2664-72.

24. Lindholm J, Juul S, Jorgensen JO, Astrup J, Bjerre P, FeldtRasmussen U, et al. Incidence and late prognosis of cushing's syndrome: a population-based study. J Clin Endocrinol Metab 2001;86:117-23.

25. Oh JS, Kim HJ, Hann HJ, Kang TU, Kim DS, Kang MJ, et al. Incidence, mortality, and cardiovascular diseases in pituitary adenoma in Korea: a nationwide population-based study. Pituitary 2021;24:38-47.

26. Swearingen B, Biller BM, Barker FG 2nd, Katznelson L, Grinspoon S, Klibanski A, et al. Long-term mortality after transsphenoidal surgery for Cushing disease. Ann Intern Med 1999;130:821-4.

27. Arafah BM. Reversible hypopituitarism in patients with large nonfunctioning pituitary adenomas. J Clin Endocrinol Metab 1986;62:1173-9.

28. Harris PE, Afshar F, Coates P, Doniach I, Wass JA, Besser $\mathrm{GM}$, et al. The effects of transsphenoidal surgery on endocrine function and visual fields in patients with functionless pituitary tumours. Q J Med 1989;71:417-27.

29. Randall RV, Scheithauer BW, Laws ER Jr, Abbound CF, Ebersold MJ, Kao PC. Pituitary adenomas associated with hyperprolactinemia: a clinical and immunohistochemical study of 97 patients operated on transsphenoidally. Mayo Clin Proc 1985;60:753-62.

30. Ezzat S, Asa SL, Couldwell WT, Barr CE, Dodge WE, Vance ML, et al. The prevalence of pituitary adenomas: a systematic review. Cancer 2004;101:613-9.

31. National Health Insurance Service. National Health Insurance System of Korea [Internet]. Wonju: NHIS; 2015 [cited 2021 May 20]. Available from: https://www.kobia.kr/bbs/ download.php?tbl=policy_report\&no=401.

32. Cheol Seong S, Kim YY, Khang YH, Heon Park J, Kang HJ, Lee H, et al. Data resource profile: the National Health Information Database of the National Health Insurance Service in South Korea. Int J Epidemiol 2017;46:799-800. 